\section{Middle East Respiratory Syndrome Coronavirus Antibodies in Dromedary Camels, Bangladesh, 2015}

\author{
Ariful Islam, Jonathan H. Epstein, \\ Melinda K. Rostal, Shariful Islam, \\ Mohammed Ziaur Rahman, \\ Mohammed Enayet Hossain, M.Salim Uzzaman, \\ Vincent J. Munster, Malik Peiris, \\ Meerjady Sabrina Flora, Mahmudur Rahman, \\ Peter Daszak
}

Author affiliations: EcoHealth Alliance, New York, New York, USA (A. Islam, J.H. Epstein, M.K. Rostal, S. Islam, P. Daszak); Institute of Epidemiology, Disease Control and Research, Dhaka, Bangladesh (S. Islam, M.S. Uzzaman, M.S. Flora, M. Rahman); icddr,b, Dhaka (M.Z. Rahman, M.E. Hossain); National Institutes of Health, Hamilton, Montana, USA (V.J. Munster); University of Hong Kong School of Public Health, Hong Kong, China (M. Peiris)

DOI: https://doi.org/10.3201/eid2405.171192

Dromedary camels are bred domestically and imported into Bangladesh. In 2015, of 55 camels tested for Middle East respiratory syndrome coronavirus in Dhaka, 17 (31\%) were seropositive, including 1 bred locally. None were PCR positive. The potential for infected camels in urban markets could have public health implications and warrants further investigation.

$\mathrm{M}$ iddle East respiratory syndrome coronavirus (MERS$\mathrm{CoV}$ ), discovered in 2012, can cause fatal respiratory disease in humans. Although MERS-CoV might have originated in bats, dromedary camels (Camelus dromedarius) are a natural host and likely source of human MERS-CoV infection $(1,2)$. Camel trade is a major driver of MERS-CoV movement between Africa and the Arabian Peninsula (3), where most human cases have occurred. Rajastan, India, is a large breeding center for dromedaries, some of which are exported to Pakistan and Bangladesh. Seropositive dromedaries have been identified in Pakistan, but little is known about MERS-CoV in other parts of South Asia (4). In Bangladesh, camels are bred on farms and imported from India for sale in seasonal markets for ritual slaughter during religious festivals. Imported camels go directly to urban markets to be sold by traders and are a separate enterprise from farmed camels.

During the September-October 2015 festival of Eidul-Adha, we collected and tested for coronaviruses the specimens of 36 dromedary camels at an urban farm and 19 camels and 18 fat-tailed sheep at an urban maket in the capital city of Dhaka (Table; online Technical Appendix,
https://wwwnc.cdc.gov/EID/article/24/5/17-1192-Techapp1. pdf). The testing was conducted as part of the US Agency for International Development's PREDICT program, which conducts surveillance in humans and animals for novel and select known zoonotic viruses, including MERS-CoV. We obtained information for each camel's origin and age from market registries or breeders' records. We also assessed and recorded the sex and apparent health status of each camel at specimen collection, at which time we collected blood, 2 nasal swab specimens, and 2 rectal swab specimens from each animal. We placed 1 set of each swab in lysis buffer $(\mathrm{Nu}-$ clisens; bioMérieux, Marcy-l'Étoile, France) and 1 in viral transport medium. We separated and froze serum samples. We extracted total nucleic acid by using EasyMag (bioMérieux) and performed cDNA synthesis by using SuperScript III first-strand synthesis supermix (Invitrogen, Carlsbad, CA, USA) according to the manufacturer's instructions. We performed pancoronavirus PCR targeting the RdRp gene (5) and MERS-CoV real-time PCR targeting the upstream envelope protein gene and nucleocapsid protein genes $\mathrm{N} 2$ and $\mathrm{N} 3(6)$. We screened serum samples by using a MERS-CoV ELISA (7) and confirmed the results by using a MERS-CoV pseudoparticle neutralization test (8).

Of the 36 camels on the farm, 24 were born there. The remaining 12 and all 19 market camels were imported from India (Table). All specimens tested negative for coronaviruses, including MERS-CoV, by PCR. ELISA showed 98.6\% specificity and sensitivity compared with the pseudoparticle neutralization test. We detected MERS-CoV antibodies in $31 \%$ (95\% CI 19\%-45\%) of camels; adults had a higher seroprevalence $(36 \%$ [95\% CI 22\%-52\%]) than juveniles ( $9 \%$ [95\% CI $0.2 \%-41 \%])$. Imported camels had a significantly higher seroprevalence $(52 \%$ [95\% CI 33\%-70\%]) than domestically bred camels (4\% [95\% CI $0.1 \%-21 \%])$. Among the 5 seropositive farm camels, 1 was a domestically bred adult, whereas the other 4 were adults from India. Camels in the market had a higher seroprevalence $(63 \%$ [95\% CI 38\%-85\%]) than those on the farm (14\% [95\% CI $5 \%-30 \%]$ ). All sheep serum samples were negative for MERS-CoV antibodies.

The findings of a higher MERS-CoV seroprevalence in adult camels (9) and the seronegativity in sheep are consistent with other studies (8). Only adult camels were found in the market. The finding of an adult seropositive camel, born on the farm, suggests that it was infected locally. No records indicate intermingling between farmed camels and those in markets. The finding of only 1 seropositive camel originating in Bangladesh suggests that if infection or exposure occurred on the farm, either viral circulation was limited or other seropositive camels had since been sold or removed. Juveniles are more likely to be actively infected than adults, and the limited juvenile sample size might explain our lack of virus detection among them (9). 
Table. Selected characteristics and MERS-CoV laboratory results for dromedary camels, Bangladesh, 2015*

\begin{tabular}{|c|c|c|c|c|}
\hline \multirow[b]{2}{*}{ Characteristic } & \multirow[b]{2}{*}{ No. (\%) camels } & \multicolumn{3}{|c|}{ No. (\%) positive for MERS-CoV, by laboratory test } \\
\hline & & rPCR (\%) & ELISA $(\%, 95 \% \mathrm{Cl})$ & ppNT $(\%, 95 \% \mathrm{Cl})$ \\
\hline \multicolumn{5}{|l|}{ All camels } \\
\hline \multicolumn{5}{|l|}{ Location } \\
\hline Farm & $36(56)$ & 0 & $6(17,6-33)$ & $5(14,5-29)$ \\
\hline Market & $19(35)$ & 0 & $11(58,34-80)$ & $12(63,38-84)$ \\
\hline \multicolumn{5}{|l|}{ Origin } \\
\hline Imported & $31(56)$ & 0 & $16(52,33-70)$ & $16(52,33-70)$ \\
\hline Bangladesh & $24(44)$ & 0 & $1(4,1-21)$ & $1(4,0-21)$ \\
\hline \multicolumn{5}{|l|}{ Sex } \\
\hline M & $29(53)$ & 0 & $6(21,8-40)$ & $7(24,10-44)$ \\
\hline $\mathrm{F}$ & $26(47)$ & 0 & $11(42,23-63)$ & $10(38,20-59)$ \\
\hline \multicolumn{5}{|l|}{ Age group } \\
\hline Adult, $\geq 2$ y & $44(80)$ & 0 & $16(36,22-52)$ & $16(36,22-52)$ \\
\hline Juvenile, $<2$ y & $11(20)$ & 0 & $1(9,1-41)$ & $1(9,0-41)$ \\
\hline \multicolumn{5}{|l|}{ Body condition } \\
\hline Poor & $19(35)$ & 0 & $11(58,34-80)$ & $12(63,38-84)$ \\
\hline Fair & $6(11)$ & 0 & $1(16,1-64)$ & 0 \\
\hline Good & $30(55)$ & 0 & $5(17,1-35)$ & $5(17,06-35)$ \\
\hline \multicolumn{5}{|c|}{ Upper respiratory signs } \\
\hline Yes & $2(4)$ & 0 & $1(50,1-99)$ & 0 \\
\hline No & $53(96)$ & 0 & $16(30,18-44$ & $17(32,20-46)$ \\
\hline \multicolumn{5}{|l|}{ Farm camels } \\
\hline \multicolumn{5}{|l|}{ Age group } \\
\hline Adult, $\geq 2$ y & $8(22)$ & 0 & 0 & 0 \\
\hline Juvenile, $<2$ y & $28(78)$ & 0 & $6(21,8-41)$ & $5(18,6-37)$ \\
\hline \multicolumn{5}{|l|}{ Sex } \\
\hline M & $18(50)$ & 0 & $1(6,1-27)$ & $4(22,6-48)$ \\
\hline$F$ & $18(50)$ & 0 & $5(28,10-53)$ & $1(6,1-27)$ \\
\hline \multicolumn{5}{|l|}{ Origin } \\
\hline Bangladesh & $24(67)$ & 0 & $1(4,1-21)$ & $1(4,1-21)$ \\
\hline Imported & $12(33)$ & 0 & $5(42,15-72)$ & $4(33,9-65)$ \\
\hline \multicolumn{5}{|l|}{ Market camels } \\
\hline \multicolumn{5}{|l|}{ Age group } \\
\hline Adult, $\geq 2 \mathrm{y}$ & $3(16)$ & 0 & $1(33,1-90)$ & $1(33,1-90)$ \\
\hline Juvenile, $<2$ y & $16(84)$ & 0 & $10(63,35-85)$ & $11(69,41-89)$ \\
\hline \multicolumn{5}{|l|}{ Sex } \\
\hline M & $11(58)$ & 0 & $6(75,23-83)$ & $6(55,23-83)$ \\
\hline $\mathrm{F}$ & $8(42)$ & 0 & $5(45,24-91)$ & $6(75,35-97)$ \\
\hline \multicolumn{5}{|l|}{ Origin } \\
\hline Bangladesh & 0 & 0 & 0 & 0 \\
\hline Imported & $19(100)$ & 0 & $11(58,34-80)$ & $12(63,38-84)$ \\
\hline
\end{tabular}

Our findings suggest transmission of MERS-CoV has occurred among camels in Bangladesh, extending the previously reported range of this virus (up to $\approx 1,900 \mathrm{~km}$ east of Pakistan). Exactly where or when imported camels became infected is unclear. To date, no human cases of MERS-CoV have been reported in South Asia. The possibility of having MERS-CoV-infected camels in Dhaka, a populous city with $\approx 18$ million persons, presents a potential risk for human outbreaks. Insufficient surveillance, behavioral differences in human-camel interactions compared with Middle Eastern societies, or differences in virus strains or human susceptibility might explain the lack of observed cases. Improved surveillance of camels along camel trade routes, camel herds in Dhaka, and persons who have close contact with camels will help assess the transboundary movement and the risk for zoonotic transmission in Bangladesh. Given the ubiquity of MERS-CoV in dromedary camels, the predictable seasonal movement of camels into Dhaka, and a higher incidence of infection in persons with frequent contact with camels (10), targeted public health messaging that promotes handwashing after contact with camels and avoidance of exposure to camel excreta might help reduce the risk for zoonotic MERS-CoV transmission.

\section{Acknowledgments}

We thank Mustafizur Rahaman, Mohammed, Amiruzzaman, Nurul Islam, Pitu Biswas, Mohammed Gaffar Sheikh, Abdul Hai, and Abdullah-Al-Mamun for assistance in the field and technical support. We thank the government of Bangladesh for permits and logistical support that made this work possible.

This study was approved by Chittagong Veterinary and Animal Sciences University, Bangladesh, and the University of Califor $\neg$ nia-Davis, Davis, California, USA (IACUC no. 16048). V.J.M. is supported by the Intramural Research Program of the National Institute of Allergy and Infectious Diseases, National Institutes of Health. This study was made possible by the 
generous support of the American people through the US Agency for International Development Emerging Pandemic Threats PREDICT project. The contents are the responsibility of the authors and do not necessarily reflect the views of the US Agency for International Development or the US Government.

\section{About the Author}

Dr. Islam is a research scientist at EcoHealth Alliance, currently working in Bangladesh as the country coordinator for the US Agency for International Development's PREDICT project. His research focuses on understanding the drivers of zoonotic disease emergence at the animal, human, and ecosystem interface.

\section{References}

1. Memish ZA, Mishra N, Olival KJ, Fagbo SF, Kapoor V, Epstein JH, et al. Middle East respiratory syndrome coronavirus in bats, Saudi Arabia. Emerg Infect Dis. 2013;19:1819-23. http://dx.doi.org/10.3201/eid1911.131172

2. Azhar EI, El-Kafrawy SA, Farraj SA, Hassan AM, Al-Saeed MS, Hashem AM, et al. Evidence for camel-to-human transmission of MERS coronavirus. N Engl J Med. 2014;370:2499-505. http://dx.doi.org/10.1056/NEJMoa1401505

3. Younan M, Bornstein S, Gluecks IV. MERS and the dromedary camel trade between Africa and the Middle East. Trop Anim Health Prod. 2016;48:1277-82. http://dx.doi.org/10.1007/ s11250-016-1089-3

4. Saqib M, Sieberg A, Hussain MH, Mansoor MK, Zohaib A, Lattwein E, et al. Serologic evidence for MERS-CoV infection in dromedary camels, Punjab, Pakistan, 2012-2015. Emerg Infect Dis. 2017;23:550-1. http://dx.doi.org/10.3201/ eid2303.161285

5. Quan PL, Firth C, Street C, Henriquez JA, Petrosov A, Tashmukhamedova A, et al. Identification of a severe acute respiratory syndrome coronavirus-like virus in a leaf-nosed bat in Nigeria. MBio. 2010;1:e0208-10, e00208-18. http://dx.doi.org/10.1128/mBio.00208-10

6. Abroug F, Slim A, Ouanes-Besbes L, Hadj Kacem MA, Dachraoui F, Ouanes I, et al.; World Health Organization Global Outbreak Alert and Response Network Middle East Respiratory Syndrome Coronavirus International Investigation Team. Family cluster of Middle East respiratory syndrome coronavirus infections, Tunisia, 2013. Emerg Infect Dis. 2014;20:1527-30. http://dx.doi.org/10.3201/eid2009.140378

7. Müller MA, Corman VM, Jores J, Meyer B, Younan M, Liljander A, et al. MERS coronavirus neutralizing antibodies in camels, Eastern Africa, 1983-1997. Emerg Infect Dis. 2014;20:2093-5. http://dx.doi.org/10.3201/eid2012.141026

8. Hemida MG, Perera RA, Wang P, Alhammadi MA, Siu LY, Li M, et al. Middle East Respiratory Syndrome (MERS) coronavirus seroprevalence in domestic livestock in Saudi Arabia, 2010 to 2013. Euro Surveill. 2013;18:20659. http://dx.doi.org/ 10.2807/1560-7917.ES2013.18.50.20659

9. Reusken CB, Raj VS, Koopmans MP, Haagmans BL. Cross-host transmission in the emergence of MERS coronavirus. Curr Opin Virol. 2016;16:55-62. http://dx.doi.org/10.1016/ j.coviro.2016.01.004

10. Hemida MG, Elmoslemany A, Al-Hizab F, Alnaeem A, Almathen F, Faye B, et al. Dromedary camels and the transmission of Middle East respiratory syndrome coronavirus (MERS-CoV). Transbound Emerg Dis. 2017;64:344-53. http://dx.doi.org/10.1111/ tbed.12401
Address for correspondence: Jonathan H. Epstein, EcoHealth Alliance, 460 W 34th St, 17th Fl, New York, NY 10019, USA; email: epstein@ecohealthalliance.org

\section{Borrelia miyamotoi sensu lato in Père David Deer and Haemaphysalis longicornis Ticks}

\author{
Yi Yang, Zhangping Yang, ${ }^{1}$ Patrick Kelly, Jing Li, \\ Yijun Ren, Chengming Wang ${ }^{1}$
}

Author affiliations: Yangzhou University College of Veterinary Medicine, Yangzhou, China (Y. Yang, J. Li, C. Wang); Jiangsu Co-innovation Center for the Prevention and Control of Important Animal Infectious Diseases and Zoonoses, Yangzhou (Y. Yang, J. Li, C. Wang); Yangzhou University College of Animal Science and Technology, Yangzhou (Z. Yang); International Corporation Laboratory of Agriculture and Agricultural Products Safety, Yangzhou University, Yangzhou (Z. Yang); Ross University School of Veterinary Medicine, Basseterre, St. Kitts and Nevis (P. Kelly); Dafeng Elk National Natural Reserve, Yancheng, China (Y. Ren); Auburn University, Auburn, Alabama, USA (C. Wang)

By sequence analysis of $16 \mathrm{~S}$ rRNA, flaB, $p 66$, and glpQ, we identified Borrelia miyamotoi in 1 of 4 Père David deer $(n=43)$ seropositive for Borrelia spp. and 1.2\% (3/244) of Haemaphysalis longicornis ticks from Dafeng Elk National Natural Reserve, China. Future studies should assess Borrelia pathogenesis in deer.

Dère David deer (Elaphurus davidianus) are extinct in the wild and found only in captivity, principally in China, England, and the United States. Just 5,000 animals remain, with $40 \%$ located in Dafeng Elk National Natural Reserve in China, which attracts $>1$ million tourists annually. Ticks are common in the Dafeng Elk National Natural Reserve (1), so we investigated the tickborne bacterial pathogens in Père David deer at this reserve.

The institutional animal care and use committee of Yangzhou University College of Veterinary Medicine (Yangzhou, China) (YZU-CVM\#2015-076) approved this study. We took whole blood samples from 43 apparently healthy Père David deer (20 males, 23 females), separated out the plasma $(1,800 \times g$ for $10 \mathrm{~min})$, and used the plasma to detect antibodies against bacterial pathogens with the

\footnotetext{
${ }^{1}$ These senior authors contributed equally to this article.
} 